\title{
Influence of Physical Exercise on Mental Health of Students in Higher Vocational Colleges and Its Teaching Inspiration
}

\section{Geli Bai}

\author{
Hanzhong Vocational and Technical College, 723000
}

Keywords: Higher vocational college students; Physical exercise; Mental health

\begin{abstract}
Physical exercise has a positive effect on students' mental health. This article analyzes and studies the effect of physical exercise on students' mental health, taking the students of Hanzhong vocational and technical colleges as an example. Based on this, it puts forward specific solutions to alleviate and solve students' psychological problems. The research content of this article provides a strong theoretical basis and guidance for the targeted development of physical education in the aspect of mental health, and serves as a reference and demonstration for the practical teaching of physical education teachers.
\end{abstract}

\section{Introduction}

The causes of mental health are complex. With the development of society, the pressure for surviving has increased and the social aspects of mental health problems have become more widespread and have shown increasing momentum year by year. Paying attention to students' mental health is not only a social issue, but also an education issue. More and more people of insight have recognized the seriousness and urgency of this issue and they have studied and attempted from theoretical level or practical level. Although it has achieved certain results, the longevity and complexity of this issue have determined that we must pay attention to it consistently. Students who have experienced the pressure of the college entrance examination may have hidden dangers in their mental health although they can relax in colleges and universities. The pressure on higher education is relatively small, but the employment pressure that students have to face has suddenly increased. In the various stages of education prior to higher education, there are few correct guidance methods for students' mental health problems, which leads to the low self-regulation ability of the students in the higher education stage. In recent years, there have been a few incidents in campus newspapers, which shows that mental health problem is a big incentive. Psychological abnormalities, psychological distortions, and even suicides have become lingering ills in colleges and universities. From this we can see that research and initiatives to strengthen students' mental health have reached a moment of urgency. The author has been engaged in education for many years and has been paying attention to students' mental health problems. As the author is engaged in physical education teaching, he has systematically researched and analyzed this problem from the perspective of his major, and strives to find practical ways to improve students' mental health.

Under the pressure of fierce social competition, both physical and psychological qualities require an external and internal adjustment. One of the important criteria of contemporary health concept is "mental health." In the physical education of colleges and universities, we are always adhering to the "health first" as the teaching goal and purpose. Physical exercise can not only improve students' physical fitness and function, but also can effectively improve students' mental health and can provide an important carrier for healthy psychological education. College sports occupies an indispensable position in the education of colleges and universities. It can not only strengthen the body but also keep a healthy mind, which is an extremely scientific and effective way to cultivate the mental health of college students. In the context of advocating quality education, college sports is not only an important part of higher education, but also an effective way to improve and strengthen students' mental health. It is the responsibility of each educator to strengthen the education of college students' psychological health, promote the development of college students' physical and mental health, and provide innovative talents with strong comprehensive abilities and 
high physical and mental qualities for social development. The author conducts analysis and research on students of vocational colleges in Hanzhong by means of investigation and research in order to discover the law and propose measures to promote the effect of improvement.

\section{Research Object and Methods}

Research Object. Select 400 students from Hanzhong Vocational and Technical College and Shaanxi Aviation Vocational and Technical College at random. At the same time, with the assistance of the counselor, 400 questionnaires on Psychological Health Symptom Checklist (scl-90) and basic physical activity surveys were issued in a unified manner to obtain basic information on the mental health status and physical activity of students in higher vocational colleges. Finally, research based on these data.

\section{Research Methods}

Literature and Data. Utilize network information, China Knowledge Online full-text database and college library to retrieve, read the master's thesis and journal paper related to this research and read information on physical exercise and mental health to provide material support for this paper.

Questionnaire. This article mainly analyzes and researches the self-made "Questionnaires on the Basic Situation of Undergraduates Participating in Physical Exercises". At the same time, we compared the comprehensive data of nine factors and ninety mental health self-evaluation items in the latest and most commonly used "Psychological Health Symptom Checklist (SCL-90)" at home and abroad. The content of the comparison analysis not only includes the body's physical symptoms, but also includes interpersonal relationships and emotional conditions, as well as their living habits. The scoring form of the questionnaire adopts a 5-point scoring system, and the level of this score is the opposite of the level of mental health.

Based on the research needs of this topic, in the three months from October to December of 2017, 200 college students from Hanzhong Vocational and Technical College and 200 college students from Shaanxi Aviation Vocational and Technical College were surveyed and statistically analyzed. The number of questionnaires for boys is 200 , and the number of questionnaires issued for girls is the same. Among them, the number of valid questionnaires for boys returned was 195, and their effective rate reached $97.5 \%$. The number of successful questionnaires for girls was 192, and the number of valid questionnaires was only 190 . The effective rate was only $95 \%$.

Comparative Analysis. To investigate and analyze the participation and status of physical education among Hanzhong vocational students, and then compare the differences between the students' physical differences and their actual mental health. At the same time, compare students of vocational colleges in the city with the national college students' physiological health level to study and analyze the average and actual differences of different factors.

Interview. Ask help and advice for Hanzhong vocational college students from senior teachers specialized in physical training and students counseling institutions as well as psychological work in teaching and the Department of student managers about the basic situation of physical exercise and mental health.

Mathematical Statistics. The scores of mental health symptoms and the basic conditions of physical exercise scores were statistically and comparatively analyzed in Excel and SPSS 11.0.

\section{Result and Analysis}

The Status of Students Participating in Physical Exercises in Higher Vocational Colleges in Hanzhong City. According to investigations, students in vocational colleges in Hanzhong accounted for $80 \%$ of the participants for physical exercise, and $16 \%$ for those with general preference, while $4 \%$ for students who did not like it. This shows that most students are more active in their favorite attitudes to physical exercise. Therefore teachers should guide them scientifically and reasonably. Among students of physical exercise, only $43 \%$ of students hold regular exercise 
(three times a week for physical exercise, more than half an hour each time). From this data, we can see that students' physical exercise attitudes are positive, but they are still lack of certain practical actions and ideas.

According to the survey data, the analysis of participation categories of male and female students in vocational colleges and universities in Hanzhong shows that boys clearly like basketball, badminton, table tennis and football, while girls prefer table tennis, running, cheerleading and aerobics. When we look into the reasons, boys are more likely to be confrontational, challenging and irritating, while girls are more likely to be relaxed and agile, or to be physically or rhythmic. It is not difficult to see from the above that the types of physical exercise selected by different students are closely related to their interests and hobbies. Therefore, the effective cultivation of students' physical exercise hobby is an important way to cultivate students' self-training habits.

Frequency and Psychological Experience of Students Participating in Physical Exercises in Higher Vocational Colleges in Hanzhong. The percentage of students who participate in physical exercise an hour more or less one time is showing as following. The number of male students who regularly participate in physical exercise accounts for $19.40 \%$ of the total number of students, and the number of students who occasionally participate in physical exercise accounts for $66.6 \%$ of the total number of students, and the number of students who never participated in physical exercise accounted for $14.0 \%$ of the total number of students. Meanwhile, the number of female students often engages in physical exercise accounted for $15.2 \%$ of the total number of students, the number of students occasionally involves in physical exercise accounted for $68.7 \%$ of the total number of students, and the number of students who never participate in physical exercise accounted for $16.1 \%$ of the total number of students. It can be seen that, in the actual situation of students participating in physical exercise in Hanzhong Vocational and Technical College, the regular participants is $17.3 \%$ of the total number of students, while the occasional participants is $67.6 \%$ of the total number of students, and it is $15.1 \%$ who hold non-physical training of the total number of students. From the specific situation of participation and the comparison of gender analysis, the number of boys in the two extremes who regularly participate in physical exercise and never participate in physical exercise exceeds the number of girls. At the same time, the number of girls who choose to participate in physical exercise occasionally is more than boys, which shows that the majority of students in vocational colleges in Hanzhong have the awareness of participating in physical exercise, but they do not make it a good habit.

Mental Health Status of Students in Vocational Colleges in Hanzhong City. The SCL-90 scale has the characteristics of large capacity, rich symptoms and more accurate characterization of subjects' subjective symptoms. If a factor score is $\geq 2$, it indicates that the factor has a slight mental health problem. If the factor score is $\geq 3$, it indicates that the degree of mental health problems of the factor is already in a medium state. Please refer to the following table 1 for specific situation.

Table 1387 students' psychological health symptom self-evaluation scale of Hanzhong Vocational and Technical College (SCL- 90)

factor $\geq 2 \geq 3$ The proportion of the number of people

\begin{tabular}{|c|c|c|c|c|}
\hline factor & $\geq 2$ & $\%$ & $\geq 3$ & $\%$ \\
\hline Somatization & 68 & 17.56 & 9 & 2.23 \\
\hline OCD & 102 & 26.4 & 11 & 2.96 \\
\hline $\begin{array}{l}\text { Relationship } \\
\text { Sensitivity }\end{array}$ & 97 & 25 & 11 & 2.8 \\
\hline Depression & 66 & 19.95 & 10 & 2.51 \\
\hline Anxiety & 72 & 18.6 & 9 & 2.4 \\
\hline Hostility & 68 & 17.5 & 9 & 2.43 \\
\hline Fear & 28 & 7.3 & 3 & 0.83 \\
\hline Paranoid & 74 & 19.2 & 9 & 2.27 \\
\hline Mental illness & 24 & 6.2 & 3 & 0.82 \\
\hline total & 139 & 0.32 & 37 & 0.095 \\
\hline
\end{tabular}

(Note: A student can have more than one factor at the same time showing as $\geq 2$ and $\geq 3$ ). 
The survey has classified students who regularly, occasionally and never participate in physical exercise into reference group. The differences in mental health levels among factors of these three types of students are also large. The order of the factors in descending is: Never participate> Occasional participation> Regular participation. According to the SCL-90 scoring criteria and its evaluation indicators, the factor score size is in contrast to the severity of the subject's mental health problems. That is to say, the smaller the factor score, the smaller the tester's mental health, it also means that it is closer to the normal state. It can be seen that the level of mental health of students who regularly participate in physical exercise is higher than students who occasionally and never participate in physical exercise. Therefore, physical exercise can improve the psychological health of college students.

Table 2 Comparison of students' mental health level who often, occasional and never participation in physical exercise in Higher vocational colleges in Hanzhong

\begin{tabular}{cccc}
\hline factor & $\begin{array}{c}\text { often } \\
(\mathrm{n}=67)\end{array}$ & $\begin{array}{c}\text { occasional } \\
(\mathrm{n}=262)\end{array}$ & $\begin{array}{l}\text { never } \\
(\mathrm{n}=58)\end{array}$ \\
\hline Somatization & 1.19 & 1.49 & 2.06 \\
OCD & 1.40 & 1.75 & 2.61 \\
Relationship Sensitivity & 1.26 & 1.69 & 2.32 \\
Depression & 1.25 & 1.61 & 2.46 \\
Anxiety & 1.23 & 1.53 & 2.28 \\
Hostility & 1.22 & 1.68 & 2.62 \\
Fear & 1.18 & 1.63 & 2.53 \\
Paranoid & 1.24 & 1.50 & 1.96 \\
Mental illness & 1.20 & 1.52 & 2.14 \\
\hline total & 1.24 & 1.60 & 2.33 \\
\hline
\end{tabular}

The score of different factors of Hanzhong higher vocational college students is higher than that of the national youth group norm, but there is a little difference of interpersonal relationship sensitivity. However, the score of other factors are much higher, which reveals that the national college students' psychological health is better than Hanzhong vocational college students. It is recommended that college students should strengthen physical exercise and develop good physical exercise habits.

Table 3 Self-evaluation Scale of Psychological Health of Hanzhong Vocational College Students (SCL- 90)

Factor scores and national norm comparison

\begin{tabular}{ccc}
\hline factor & $\begin{array}{c}\text { College Students } n=387 \\
{ }^{\prime} \mathrm{X}\end{array}$ & $\begin{array}{c}\text { National Youth } \\
\text { Group Norm } \mathrm{n}=781\end{array}$ \\
\hline Somatization & 1.44 & 'X $^{-3}$ \\
OCD & 1.83 & 1.69 \\
Relationship & 1.75 & 1.76 \\
Sensitivity & 1.67 & 1.57 \\
Depression & 1.47 & 1.42 \\
Anxiety & 1.68 & 1.50 \\
Hostility & 1.40 & 1.33 \\
Fear & 1.60 & 1.52 \\
Paranoid & 1.47 & 1.38 \\
Mental illness & &
\end{tabular}




\section{The Effect of Physical Exercise on Higher Vocational Students' Mental Health}

Physical exercise allows students to have a healthy body, but also conducive to students' mental health. People can enhance their immunity by participating in physical training while strengthening their health. Therefore, physical functions will also increase. Besides, people's mood and mentality will be relaxed through physical exercise, thus promoting the overall development of the human body. If young students can actively participate in physical exercise, it will not only contribute to physical health, but also help mental health, and the cultivation of this habit will have great benefit to their health throughout their lives.

\section{Teaching Inspiration}

There is a close relationship between mental health and physical exercise. The study of both involves a complex science and a more complex process. In order to do a good job of guiding the physical exercise in mental health, we should first of all strengthen our understanding of ideology and effectively understand the positive role of physical exercise in improving mental health. Teachers must follow the laws of science in teaching content, teaching methods and teaching methods. Second, it is necessary to strengthen the combination of training methods and training purposes. Only in this way can teachers implement orderly according to the characteristics of students' mental health. Finally, teachers must guide the improvement of student's personality in physical exercise and cultivate students' complete personality quality. Students are allowed to grow up healthy and happy in sports. Besides, students can also learn to live in harmony with others during exercise and communication, face problems properly, exercise their ability to resist frustration and understand and master how to relieve bad emotions in sports. Teachers must pay special attention to students' various problems that may arise in their mental health and make it as a part of their teaching content. At the same time, teachers should use quality education as the starting point to cultivate students' self-efficacy.

\section{Acknowledgement}

Project information: Hanzhong Vocational and Technical College Institute of Teaching and Research in 2017

Project name: Influence of Physical Exercise on Students' Mental Health in Higher Vocational Colleges

Project approval number HZYKYYB201701

\section{Reference}

[1] L. W. Zhang and W. D. Ren. Progress in Sports Psychology [M]. Beijing: Higher Education Press, 2001.

[2] L. Ji. Physical Training and Mental Health [M]. Shanghai: East China Normal University Press, 2006:131-132.

[3] R. P. Wang. Physical Training and Mental Health [M]. Guilin: Guangxi Normal University Press, 2005: 121-123.

[4] X. M. Zheng. Research on the Influence of College Physical Education on Mental Health of University Students in China[D]. Master's Thesis of Sichuan University, 2006.

[5] J. B. Luo and Y. Z. Li. On the Influence of Sports Activities on College Students' Mental Health [J]. Sport Science and Technology, 2005, 26(4): 60-63.

[6] H. Y. Wang. Influence of Physical Exercise on College Students' Mental Health [J]. Occupation and Health, 2017, 33(3): 396-398.

[7] L. S. Pi. Psychology of Learning and Teaching [M]. Shanghai: East China Normal University Press, 1997.

[8] J. Yan. Sports Psychology [M]. Beijing: Hohai University Press, 2001. 